\title{
Coupling of acyl chlorides with triarylbismuths catalyzed by palladium bipyridyl complex anchored on nanosized MCM-41: A recyclable and atom-efficient catalytic process for the synthesis of diaryl and alkyl aryl ketones
}

\author{
Jun-You Chen ${ }^{a}$, Szu-Chien Chen ${ }^{a}$, Yun-Ju Tang ${ }^{a}$, Chung-Yuan Mou ${ }^{b}$, Fu-Yu Tsai ${ }^{\text {a,* }}$ \\ a Institute of Organic and Polymeric Materials, National Taipei University of Technology, 1, Sec. 3, Chung-Hsiao E. Rd., Taipei 106, Taiwan \\ ${ }^{\mathrm{b}}$ Department of Chemistry, National Taiwan University, Taipei 106, Taiwan
}

\section{A R T I C L E I N F O}

\section{Article history:}

Received 4 September 2008

Received in revised form 20 January 2009

Accepted 6 March 2009

Available online 20 March 2009

\section{Keywords:}

Mesoporous silica

Palladium complex

Cross-coupling

Ketones

Recyclable catalyst

\begin{abstract}
A B S T R A C T
The coupling reactions of acyl chlorides with triarylbismuths catalyzed by a palladium bipyridyl complex anchored on nanosized mesoporous silica MCM-41 gave diaryl and alkyl aryl ketones in good to high yields. The amount of triarylbismuths required for the cross-coupling could be up to half the molar ratio relative to the acyl chlorides for the completion of the reaction; the catalyst could be recovered and reused after the reaction, providing both an atom-efficient and catalyst-recyclable process for the synthesis of diaryl and alkyl aryl ketones.
\end{abstract}

(c) 2009 Elsevier B.V. All rights reserved.

\section{Introduction}

Friedel-Crafts acylation in the presence of Lewis acids is one of the most useful synthetic methods for the preparation of aromatic ketones [1,2]. Because the substituents on the aromatic ring affect the rate of Friedel-Crafts acylation and the regioselectivity, transition-metal-catalyzed formation of aromatic ketones seems to be a better strategy for this purpose [3]. Among many methods, the palladium-catalyzed coupling reaction of acyl chlorides with organometallic reagents is one of the most efficient methods for aromatic ketone synthesis. The mechanism involves the oxidative addition of acyl chlorides to palladium, the transmetalation of the organic group from organometallic reagent to an acyl palladium species, and subsequent reductive elimination, giving the aromatic ketone. Organoboron [4-13], organotin [14,15] and organozinc [1,2] reagents have been used as organometallic reagents for the synthesis of ketones. Although these reagents are well-documented with regards to their use in transmetalation, only one equivalent of the organic group can be used for the cross-coupling reaction. Recently, triarylbismuths have been employed to couple with acyl chlorides on the basis of atom-efficient considerations, as three equivalents of the aryl groups on bismuth can be transferred to the transi-

\footnotetext{
* Corresponding author. Fax: +886227317174.

E-mail address: fuyutsai@ntut.edu.tw (F.-Y. Tsai).
}

tion metal [16-18]. For this reason, less than equivalent quantity of triarylbismuth is needed for the cross-coupling reaction.

Because of economic concerns, the development of a recyclable catalyst, as well as the use of atom-efficient triarylbismuths, for the synthesis of ketones is much desired. Previously, Zhang's group has reported the use of a recyclable palladium catalyst system in PEG or ionic liquid to obtain ketones by the coupling of carboxylic anhydrides or acyl chlorides and arylboronic acids, stoichiometric amounts of arylboronic acids are required [12]. On the other hand, ordered mesoporous silica (OMS) is a good choice as a solid support for the purpose of recovery and recyclability. OMS materials with a uniform pore diameter, high surface area, and large number of silanol groups are ideal supports for immobilizing transition metal complexes, and the heterogenized catalysts may be easily separated from the reaction mixture [19-32]. The catalyst-immobilization techniques of recyclable palladium complexes for $\mathrm{C}-\mathrm{C}$ bond formation have been developed for the Mizoroki-Heck reaction [33-43], Suzuki-Miyaura reaction [44-48], Sonogashira coupling [49-51], indole formation [52], Kumada-Tamao-Corriu reaction [53], and Migita-Kosugi-Stille reaction [54]. We have previously reported that the nanosized OMS-grafted palladium bipyridyl complex NSMCM-41-Pd is a highly efficient and recyclable catalyst for the Mizoroki-Heck [39] and Kumada-Tamao-Corriu [53] reactions. The fundamental advantage of this catalyst is that the short and highly connected wormhole-like channels of nanosized MCM-41 lead to easy exchange of reactants, salts and products through- 


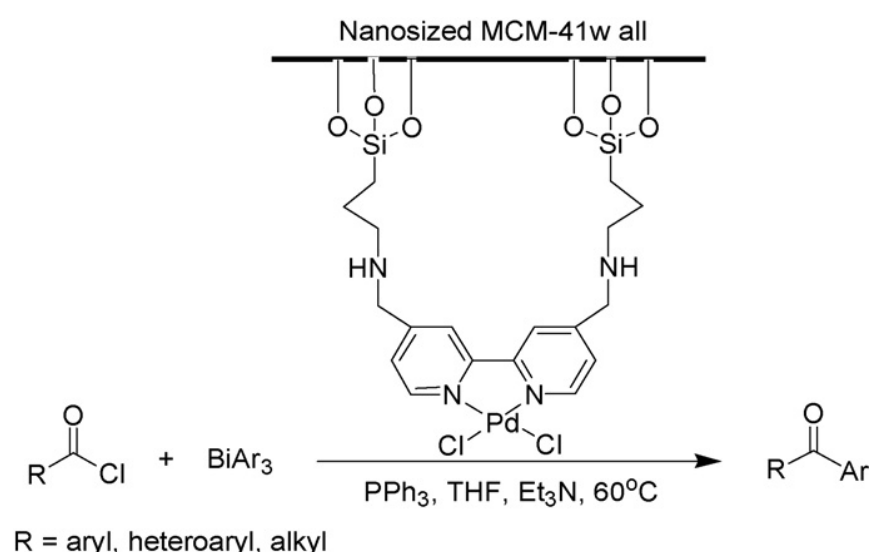

Scheme 1. NS-MCM-41-Pd-catalyzed coupling of acyl chlorides with triarylbismuths.

out the nanochannels. Thus, a very low catalyst loading can be applied in the reaction. In this report, we present a diaryl and alkyl aryl ketone synthesis procedure that not only uses triarylbismuths as atom-efficient organometallic reagents but also employs a nanosized MCM-41 supported palladium bipyridyl complex as a recyclable catalyst (Scheme 1 ).

\section{Experimental}

\subsection{General information}

All reactions involving air- and moisture-sensitive conditions were carried out in a dry nitrogen atmosphere. The chemicals were purchased from commercial suppliers and were used
Table 1

Optimization of reaction conditions for the coupling of benzoyl chloride with triphenylbismutha ${ }^{\mathrm{a}}$.

\begin{tabular}{cllll}
\hline Entry & Solvent & Base (equivalent) & $T\left({ }^{\circ} \mathrm{C}\right)$ & Yield $(\%)^{\mathrm{b}}$ \\
\hline 1 & $\mathrm{THF}$ & $\mathrm{Et}_{3} \mathrm{~N}(2)$ & 60 & 70 \\
2 & $\mathrm{THF}$ & $\mathrm{Bu}_{3} \mathrm{~N}(2)$ & 60 & 65 \\
3 & $\mathrm{DME}$ & $\mathrm{Et}_{3} \mathrm{~N}(2)$ & 80 & 45 \\
4 & $1,4-$ Dioxane & $\mathrm{Et}_{3} \mathrm{~N}(2)$ & 80 & 24 \\
5 & Toluene & $\mathrm{Et}_{3} \mathrm{~N}(2)$ & 100 & 58 \\
$6^{\mathrm{c}}$ & $\mathrm{THF}$ & $\mathrm{Et}_{3} \mathrm{~N}(2)$ & 60 & 99 \\
$7^{\mathrm{c}}$ & $\mathrm{THF}$ & $\mathrm{Et}_{3} \mathrm{~N}(2)$ & $\mathrm{rt}$ & 0 \\
$8^{\mathrm{c}}$ & $\mathrm{THF}$ & $\mathrm{Et}_{3} \mathrm{~N}(1)$ & 60 & 50 \\
$9^{\mathrm{c}}$ & $\mathrm{THF}$ & $\mathrm{Et}_{3} \mathrm{~N}(3)$ & 60 & 70 \\
$10^{\mathrm{c}}$ & $\mathrm{THF}$ & $\mathrm{Et}_{3} \mathrm{~N}(4)$ & 60 & 45 \\
$11^{\mathrm{c}}$ & $\mathrm{THF}$ & $\mathrm{K}_{2} \mathrm{CO}(2)$ & 60 & 83 \\
$12^{\mathrm{c}}$ & $\mathrm{THF}$ & $\mathrm{NaOAc}_{3}(2)$ & 60 & 57 \\
$13^{\mathrm{c}, \mathrm{d}}$ & $\mathrm{THF}$ & $\mathrm{Et}_{3} \mathrm{~N}(2)$ & 60 & 5 \\
$14^{\mathrm{c}, \mathrm{e}}$ & $\mathrm{THF}$ & $\mathrm{Et}_{3} \mathrm{~N}(2)$ & 60 & 88 \\
\hline
\end{tabular}

a Reaction conditions: $\left[\mathrm{C}_{6} \mathrm{H}_{5} \mathrm{COCl}\right]:\left[\mathrm{Ph}_{3} \mathrm{Bi}\right]:\left[\mathrm{PPh}_{3}\right]:[\mathrm{Pd}]=100: 35: 2: 1$. Reaction time $=12 \mathrm{~h}$.

b $\mathrm{GC}$ yields.

c $\left[\mathrm{C}_{6} \mathrm{H}_{5} \mathrm{COCl}\right]:\left[\mathrm{Ph}_{3} \mathrm{Bi}\right]:\left[\mathrm{PPh}_{3}\right]:[\mathrm{Pd}]=100: 50: 2: 1$.

${ }^{d}$ In the absence of $\mathrm{PPh}_{3}$.

e $\mathrm{PdCl}_{2}$ (bpy) was used as the catalyst.

without further purification. THF, 1,4-dioxane, DME and toluene were distilled from sodium benzophenone ketyl. $\mathrm{Et}_{3} \mathrm{~N}, \mathrm{Bu}_{3} \mathrm{~N}$, and diisopropylethylamine were dried over $\mathrm{KOH}$ and then distilled. 4,4'-Bis(bromomethyl)-2,2'-bipyridine [55,56], $\mathrm{PdCl}_{2}(\mathrm{PhCN})_{2}$ [57], triarylbismuth [58,59], and nanosized MCM-41 [60] were prepared according to known procedures. The detailed procedure for the preparation of NS-MCM-41-Pd was reported in our previously published paper [53]. Melting points were recorded using melting point apparatus and were uncorrected. Powder X-ray diffraction patterns were acquired on a PANalytical X'Pert PRO (45 kV, $40 \mathrm{~mA})$ with $\mathrm{Cu}$

Table 2

NS-MCM-41-Pd-catalyzed coupling of acyl chlorides with triarylbismuths ${ }^{\mathrm{a}}$.

\begin{tabular}{|c|c|c|c|c|c|}
\hline Entry & Acyl chloride & $\mathrm{Ar}_{3} \mathrm{Bi}$ & $\operatorname{Pd}(\mathrm{mol} \%)^{\mathrm{b}}$ & $t(\mathrm{~h})$ & Yield $(\%)^{c}$ \\
\hline 1 & Benzoyl chloride & $\left(\mathrm{C}_{6} \mathrm{H}_{5}\right)_{3} \mathrm{Bi}$ & 0.2 & 24 & $68(61)$ \\
\hline 2 & Benzoyl chloride & $\left(4-\mathrm{MeC}_{6} \mathrm{H}_{4}\right)_{3} \mathrm{Bi}$ & 1 & 12 & $93(83)$ \\
\hline 3 & Benzoyl chloride & $\left(4-\mathrm{FC}_{6} \mathrm{H}_{4}\right)_{3} \mathrm{Bi}$ & 1 & 24 & $75(66)$ \\
\hline 4 & p-Toluoyl chloride & $\left(\mathrm{C}_{6} \mathrm{H}_{5}\right)_{3} \mathrm{Bi}$ & 1 & 18 & $99(83)$ \\
\hline 5 & p-Toluoyl chloride & $\left(4-\mathrm{MeC}_{6} \mathrm{H}_{4}\right)_{3} \mathrm{Bi}$ & 0.2 & 32 & $72(66)$ \\
\hline 6 & p-Toluoyl chloride & $\left(4-\mathrm{FC}_{6} \mathrm{H}_{4}\right)_{3} \mathrm{Bi}$ & 1 & 9 & $73(60)$ \\
\hline 7 & m-Toluoyl chloride & $\left(\mathrm{C}_{6} \mathrm{H}_{5}\right)_{3} \mathrm{Bi}$ & 1 & 24 & $93(82)$ \\
\hline 8 & m-Toluoyl chloride & $\left(4-\mathrm{MeC}_{6} \mathrm{H}_{4}\right)_{3} \mathrm{Bi}$ & 1 & 24 & $99(86)$ \\
\hline 9 & m-Toluoyl chloride & $\left(4-\mathrm{MeC}_{6} \mathrm{H}_{4}\right)_{3} \mathrm{Bi}$ & 0.2 & 24 & $57(52)$ \\
\hline 10 & m-Toluoyl chloride & $\left(4-\mathrm{FC}_{6} \mathrm{H}_{4}\right)_{3} \mathrm{Bi}$ & 1 & 9 & $60(47)$ \\
\hline 11 & $o$-Toluoyl chloride & $\left(\mathrm{C}_{6} \mathrm{H}_{5}\right)_{3} \mathrm{Bi}$ & 1 & 24 & $65(56)$ \\
\hline 12 & o-Toluoyl chloride & $\left(4-\mathrm{MeC}_{6} \mathrm{H}_{4}\right)_{3} \mathrm{Bi}$ & 1 & 24 & $89(74)$ \\
\hline 13 & o-Toluoyl chloride & $\left(4-\mathrm{FC}_{6} \mathrm{H}_{4}\right)_{3} \mathrm{Bi}$ & 1 & 12 & $61(51)$ \\
\hline 14 & 4-Methoxybenzoyl chloride & $\left(\mathrm{C}_{6} \mathrm{H}_{5}\right)_{3} \mathrm{Bi}$ & 1 & 12 & $84(72)$ \\
\hline 15 & 4-Methoxybenzoyl chloride & $\left(4-\mathrm{MeC}_{6} \mathrm{H}_{4}\right)_{3} \mathrm{Bi}$ & 1 & 24 & $96(91)$ \\
\hline 16 & 4-Methoxybenzoyl chloride & $\left(4-\mathrm{MeC}_{6} \mathrm{H}_{4}\right)_{3} \mathrm{Bi}$ & 0.2 & 48 & $88(83)$ \\
\hline 17 & 4-Methoxybenzoyl chloride & $\left(4-\mathrm{FC}_{6} \mathrm{H}_{4}\right)_{3} \mathrm{Bi}$ & 1 & 12 & $70(61)$ \\
\hline 18 & 4-Nitrobenzoyl chloride & $\left(\mathrm{C}_{6} \mathrm{H}_{5}\right)_{3} \mathrm{Bi}$ & 1 & 12 & $76(68)$ \\
\hline 19 & 4-Nitrobenzoyl chloride & $\left(\mathrm{C}_{6} \mathrm{H}_{5}\right)_{3} \mathrm{Bi}$ & 0.2 & 48 & $61(57)$ \\
\hline 20 & 4-Nitrobenzoyl chloride & $\left(4-\mathrm{MeC}_{6} \mathrm{H}_{4}\right)_{3} \mathrm{Bi}$ & 1 & 12 & $98(91)$ \\
\hline 21 & 4-Nitrobenzoyl chloride & $\left(4-\mathrm{FC}_{6} \mathrm{H}_{4}\right)_{3} \mathrm{Bi}$ & 1 & 12 & $80(66)$ \\
\hline 22 & 4-Chlorobenzoyl chloride & $\left(\mathrm{C}_{6} \mathrm{H}_{5}\right)_{3} \mathrm{Bi}$ & 1 & 9 & $90(80)$ \\
\hline 23 & 4-Chlorobenzoyl chloride & $\left(4-\mathrm{MeC}_{6} \mathrm{H}_{4}\right)_{3} \mathrm{Bi}$ & 1 & 12 & $81(70)$ \\
\hline 24 & 4-Chlorobenzoyl chloride & $\left(4-\mathrm{MeC}_{6} \mathrm{H}_{4}\right)_{3} \mathrm{Bi}$ & 0.2 & 32 & $72(68)$ \\
\hline 25 & 4-Chlorobenzoyl chloride & $\left(4-\mathrm{FC}_{6} \mathrm{H}_{4}\right)_{3} \mathrm{Bi}$ & 1 & 12 & $54(49)$ \\
\hline 26 & 2-Chlorobenzoyl chloride & $\left(\mathrm{C}_{6} \mathrm{H}_{5}\right)_{3} \mathrm{Bi}$ & 1 & 12 & $68(62)$ \\
\hline 27 & 2-Chlorobenzoyl chloride & $\left(4-\mathrm{MeC}_{6} \mathrm{H}_{4}\right)_{3} \mathrm{Bi}$ & 1 & 12 & $65(56)$ \\
\hline 28 & 2-Chlorobenzoyl chloride & $\left(4-\mathrm{FC}_{6} \mathrm{H}_{4}\right)_{3} \mathrm{Bi}$ & 1 & 12 & $70(65)$ \\
\hline 29 & 4-Bromobenzoyl chloride & $\left(\mathrm{C}_{6} \mathrm{H}_{5}\right)_{3} \mathrm{Bi}$ & 1 & 12 & $82(71)$ \\
\hline 30 & 4-Bromobenzoyl chloride & $\left(4-\mathrm{MeC}_{6} \mathrm{H}_{4}\right)_{3} \mathrm{Bi}$ & 1 & 12 & $89(81)$ \\
\hline 31 & 4-Bromobenzoyl chloride & $\left(4-\mathrm{FC}_{6} \mathrm{H}_{4}\right)_{3} \mathrm{Bi}$ & 1 & 12 & $88(78)$ \\
\hline
\end{tabular}

a Reaction conditions: in THF at $60^{\circ} \mathrm{C}$. [Acyl chloride]: $\left[\mathrm{Ar}_{3} \mathrm{Bi}\right]:\left[\mathrm{Et}_{3} \mathrm{~N}\right]=2: 1: 4$

b Based on acyl chloride.

c GC yields. Isolated yields are given in parentheses. 
$\mathrm{K} \alpha$ radiation $(\lambda=0.1541 \mathrm{~nm}) . \mathrm{N}_{2}$ adsorption-desorption isotherms were obtained at $77 \mathrm{~K}$ on a Micromeritics ASAP 2010 analyzer. Before sorption measurements, the calcined NS-MCM-41 and palladium complex grafted NS-MCM-41 were degassed at $150^{\circ} \mathrm{C}$ for more than $6 \mathrm{~h}$ under a $10^{-3}$-Torr pressure. All ${ }^{1} \mathrm{H}$ and ${ }^{13} \mathrm{C}$ NMR spectra were recorded in $\mathrm{CDCl}_{3}$ or $\mathrm{C}_{6} \mathrm{D}_{6}$ solutions at $25^{\circ} \mathrm{C}$ on Varian 200 NMR spectrometers. GC analysis was performed on an SRI 8610C equipped with a fused silica capillary column. All cross-coupling products were known compounds and their spectra were in agreement with the authentic samples.

\subsection{General procedure for the coupling of acyl chlorides with triarylbismuths}

Under a nitrogen atmosphere, a Schlenk tube was charged with NS-MCM-41-Pd (100 mg, $0.015 \mathrm{mmol}), \mathrm{PPh}_{3}(7.9 \mathrm{mg}, 0.03 \mathrm{mmol}$ ), triarylbismuth $(0.75 \mathrm{mmol}), \mathrm{Et}_{3} \mathrm{~N}(0.42 \mathrm{~mL}, 3.0 \mathrm{mmol}), \mathrm{THF}(5 \mathrm{~mL})$, and acyl chloride $(1.5 \mathrm{mmol})$ and the reaction mixture was stirred at $60^{\circ} \mathrm{C}$. The reaction was monitored by GC in the presence of dodecane $(0.17 \mathrm{~mL}, 0.75 \mathrm{mmol}$ ) as an internal standard after $12 \mathrm{~h}$ (for Table 1 ), $24 \mathrm{~h}$ (for Table 3 ), or specific reaction time (for Table 2 ). After cooling to room temperature, $3 \mathrm{~N} \mathrm{HCl}$ was added and the organic product was extracted with EtOAc. The organic layer was dried over $\mathrm{MgSO}_{4}$ and the solvent was removed in a vacuum. Column chromatography on silica gel afforded the desired product. All isolated products were determined by ${ }^{1} \mathrm{H}$ NMR and ${ }^{13} \mathrm{C}$ NMR spectroscopies.

\subsection{Experimental procedure for the recycling of NS-MCM-41-Pd}

This was conducted as described above; benzoyl chloride and triphenylbismuth were used in this case. The reaction time for each cycle was fixed to $12 \mathrm{~h}$. After determining the yield by GC, the catalyst was recovered by centrifugation, washed with $3 \mathrm{~N} \mathrm{HCl}$ aqueous solution and THF twice ( $10 \mathrm{~mL}$ for each wash), and dried in a vacuum overnight. The recovered catalyst was then re-used in the same reaction.

\section{Results and discussion}

\subsection{Optimization of reaction conditions for the coupling of benzoyl chloride and triphenylbismuth}

The catalyst NS-MCM-41-Pd was prepared according to our previously published procedure [39,53]. After the grafting of the palladium bipyridyl complex onto NS-MCM-41, the surface area and pore diameter decreased from $705 \mathrm{~m}^{2} / \mathrm{g}$ and $2.5 \mathrm{~nm}$ to $588 \mathrm{~m}^{2} / \mathrm{g}$ and $2.3 \mathrm{~nm}$, respectively. The amount of Pd complex anchored on the wall of MCM-41 was estimated to be $0.15 \mathrm{mmol} / \mathrm{g}$ by ICPMASS analysis. At the outset, the coupling of benzoyl chloride with triphenylbismuth catalyzed by NS-MCM-41-Pd was examined; the results are summarized in Table 1 . Our initial experiment was conducted with benzoyl chloride, $35 \mathrm{~mol} \%$ triphenylbismuth, and $1 \mathrm{~mol} \%$ NS-MCM-41-Pd in THF at $60^{\circ} \mathrm{C}$ for $12 \mathrm{~h}$, and a $70 \%$ GC yield was observed in the presence of 2 equivalents of $\mathrm{Et}_{3} \mathrm{~N}$ (Table 1, Entry 1). There was no improvement of yield when $\mathrm{Bu}_{3} \mathrm{~N}$ was employed as a base (Entry 2). When other organic solvents such as DME, 1,4-dioxane and toluene were used with an elevated reaction temperature, the yields were lower than in THF (Entries 3-5). The yield of benzophenone was improved to near quantitative by increasing the amount of triphenylbismuth from 35 to $50 \mathrm{~mol} \%$ (Entry 6). However, no desired product resulted when the reaction was conducted at room temperature (Entry 7). Decreasing or increasing the amounts of base did not improve the formation of benzophene, giving yields between 45 and 70\% (Entries 8-10). In contrast to our previous report on the Heck reaction [39], inorganic bases such as

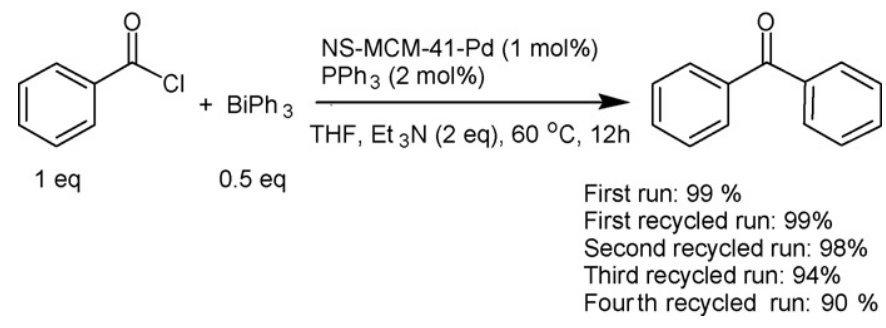

Scheme 2. Recycling studies of the NS-MCM-41-Pd-catalyzed coupling of benzoyl chloride with triphenylbismuth.

$\mathrm{K}_{2} \mathrm{CO}_{3}$ and NaOAc were effective for the reaction and afforded the products in 83 and $57 \%$ yields, respectively (Entries 11-12). Notably, the presence of $\mathrm{PPh}_{3}$ was critical, and we have previously reported that it may stabilize the $\operatorname{Pd}(0)$ species before its oxidative addition with organic halides [53]. Under identical conditions, only $5 \%$ of benzophenone was observed in the absence of $\mathrm{PPh}_{3}$ (Entry 13). For comparison, $\mathrm{PdCl}_{2}$ (bpy) was used as the catalyst for this reaction, and it was found that $88 \%$ product yield was obtained after $12 \mathrm{~h}$, indicating that the heterogenization of the palladium catalyst did not decrease its activity (Entry 14).

\subsection{Recycling studies on NS-MCM-41-Pd}

After optimization of the reaction conditions, we examined the recyclability of NS-MCM-41-Pd. Under the previously described optimum reaction conditions of Entry 6 of Table 1, the mixture of the first-run reaction was centrifuged and the collected solid was washed alternately with $3 \mathrm{~N} \mathrm{HCl}$ and THF twice. After drying under vacuum, the recovered NS-MCM-41-Pd was then re-used in the same reaction; it was found that NS-MCM-41-Pd showed only a slight decrease in activity after four recycle runs, indicating that this catalyst is stable upon workup (Scheme 2). The powder X-ray diffraction patterns shown in Fig. 1 demonstrate that the structure of NS-MCM-41-Pd remained intact after recycling further demonstrating the stability of this solid support.

Next, a hot-filtration experiment was performed in order to demonstrate that the reaction proceeded by heterogeneous catalysis [34-40,43-49,52-54]. We ran a reaction for the coupling of benzoyl chloride and triphenylbismuth catalyzed by NS-MCM-41Pd but stopped at $3 \mathrm{~h}$ resulting in the formation of benzophenone in a $43 \%$ yield. The reaction mixture was filtered promptly through a dried Celite pad under nitrogen to remove any undissolved fine particles. The clear filtrate was then stirred at $60^{\circ} \mathrm{C}$ and the prod-

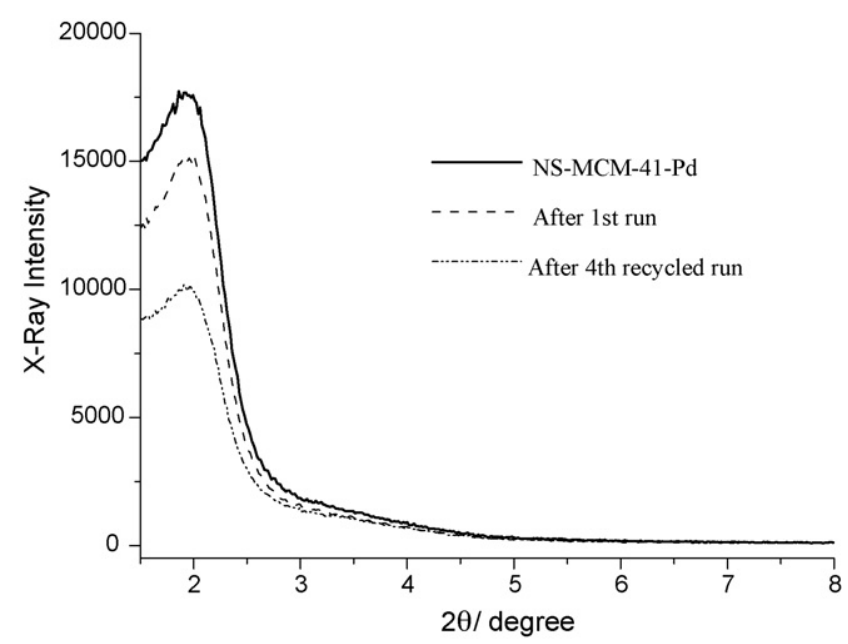

Fig. 1. The XRD patterns of freshly prepared and recycled NS-MCM-41-Pd. 
Table 3

NS-MCM-41-Pd-catalyzed coupling of heteroaryl and alkyl acyl chlorides with triarylbismuths ${ }^{\mathrm{a}}$.

\begin{tabular}{|c|c|c|c|c|}
\hline Entry $^{\mathrm{a}}$ & Acyl chloride & $\mathrm{Ar}_{3} \mathrm{Bi}$ & $\mathrm{Pd}(\mathrm{mol} \%)^{\mathrm{b}}$ & Yield $(\%)^{c}$ \\
\hline 1 & 2-Furoyl chloride & $\left(\mathrm{C}_{6} \mathrm{H}_{5}\right)_{3} \mathrm{Bi}$ & 1 & $91(88)$ \\
\hline 2 & 2-Furoyl chloride & $\left(4-\mathrm{MeC}_{6} \mathrm{H}_{4}\right)_{3} \mathrm{Bi}$ & 1 & $99(91)$ \\
\hline 3 & 2-Furoyl chloride & $\left(4-\mathrm{FC}_{6} \mathrm{H}_{4}\right)_{3} \mathrm{Bi}$ & 1 & $99(93)$ \\
\hline 4 & 2-Thiophenecarbonyl chloride & $\left(\mathrm{C}_{6} \mathrm{H}_{5}\right)_{3} \mathrm{Bi}$ & 1 & $99(95)$ \\
\hline 5 & 2-Thiophenecarbonyl chloride & $\left(4-\mathrm{MeC}_{6} \mathrm{H}_{4}\right)_{3} \mathrm{Bi}$ & 1 & $99(94)$ \\
\hline 6 & 2-Thiophenecarbonyl chloride & $\left(4-\mathrm{FC}_{6} \mathrm{H}_{4}\right)_{3} \mathrm{Bi}$ & 1 & $99(96)$ \\
\hline $7^{d}$ & Valeroyl chloride & $\left(\mathrm{C}_{6} \mathrm{H}_{5}\right)_{3} \mathrm{Bi}$ & 1 & $69(61)$ \\
\hline $8^{d}$ & Valeroyl chloride & $\left(4-\mathrm{MeC}_{6} \mathrm{H}_{4}\right)_{3} \mathrm{Bi}$ & 1 & $75(70)$ \\
\hline $9^{d}$ & Valeroyl chloride & $\left(4-\mathrm{FC}_{6} \mathrm{H}_{4}\right)_{3} \mathrm{Bi}$ & 1 & $64(56)$ \\
\hline
\end{tabular}

a Reaction conditions: in THF at $60^{\circ} \mathrm{C}$. [Acyl chloride]: $\left[\mathrm{Ar}_{3} \mathrm{Bi}\right]:\left[\mathrm{Et}_{3} \mathrm{~N}\right]=2: 1: 4$. Reaction time $=24 \mathrm{~h}$.

b Based on acyl chloride.

c GC yields. Isolated yields are given in parentheses.

d Diisopropylethylamine was used as the base.

uct yield was monitored by GC every hour until $12 \mathrm{~h}$. As shown in Fig. 2, the yields fluctuate between 42 and $46 \%$ during this long period. Compared with the reaction without hot filtration, the yield should have been $99 \%$ by $12 \mathrm{~h}$ (Scheme 2 , first run). That the yields did not increase after hot filtration indicated a very low activity of the filtrate, thus implying that the loss of Pd into the solution during the reaction is slight. Furthermore, we did check the Pd content in the filtrate and found only $0.3 \mathrm{ppm}$ of palladium in the liquid solution. Therefore, there were little loss of Pd into the solution and the catalytic activity of NS-MCM-41-Pd indeed came from the immobilized Pd complex.

\subsection{NS-MCM-41-Pd-catalyzed coupling of acyl chlorides and triarylbismuths}

Under the optimized reaction conditions, we explored the application scope of this method. $\mathrm{BiPh}_{3}, \mathrm{Bi}(p \text {-tolyl })_{3}$, and $\operatorname{Bi}(p$ fluorophenyl $)_{3}$ were chosen as representative triarylbismuths to study the activity of NS-MCM-41-Pd for the coupling with various acyl chlorides. The results are shown in Table 2. Benzoyl chloride coupled with triarylbismuths efficiently, giving high yields of the corresponding diaryl ketones (Table 2, Entries 1-3). Moreover, the loading amount of the catalyst could be further reduced to

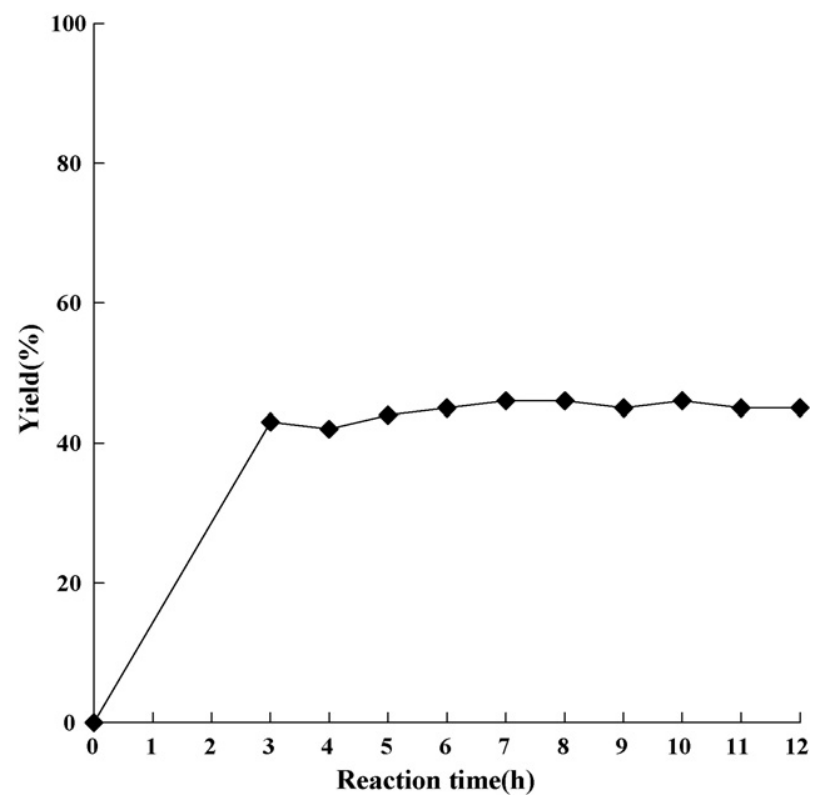

Fig. 2. Plot of yields versus time for the hot-filtration experiment. The NS-MCM$41-\mathrm{Pd}$ was filtered off after $3 \mathrm{~h}$ of reaction at $60^{\circ} \mathrm{C}$. $\left[\mathrm{C}_{6} \mathrm{H}_{5} \mathrm{COCl}\right]:\left[\mathrm{Ph}_{3} \mathrm{Bi}\right]:\left[\mathrm{PPh}_{3}\right]$ : $[P d]=100: 50: 2: 1$.
$0.2 \mathrm{~mol} \%$ for the coupling of benzoyl chloride with triphenylbismuth. This method is applicable to various toluoyl chlorides; good to high yields were obtained for the formation of diaryl ketones using catalyst loadings of between 0.2 and $1 \mathrm{~mol} \%$ (Entries 4-13). In addition, acyl chlorides with electron-donating and electronwithdrawing groups at the para-position showed similar activities. The results in Entries 14-21 illustrate that the steric and electronic factors of the acyl chlorides had only a small influence in this reaction giving the same results as the reaction occurring under homogeneous conditions [17-18]. Efficient and chemoselective cross-coupling was also observed successfully with halobenzoyl chlorides, as the oxidative addition of acyl chloride to palladium occurs prior to that of aryl halides at $60^{\circ} \mathrm{C}$. Halo-substituted benzophenones were obtained as single products in good to high yields (Entries 22-31).

To extend the scope of this reaction, cross-couplings of heteroaroyl chlorides and alkyl acyl chloride were studied. As shown in Table 3, 2-furoyl chloride and 2-thiophenecarbonyl chloride were found to couple with different triarylbismuths very efficiently to give excellent yields (Entries 1-6). However, when an alkyl acyl chloride such as valeroyl chloride was employed, no desired product was observed. Several reports show that $\mathrm{Et}_{3} \mathrm{~N}$ reacts with linear aliphatic acyl chlorides to form ketenes and subsequent [2+2] cycloaddition gave oxetanes [61-63]. Replacing $\mathrm{Et}_{3} \mathrm{~N}$ with bulky diisopropylethylamine as a base avoided the side reaction and the desired alkyl aryl ketones were obtained in good yields (Entries 7-9).

\section{Conclusion}

In conclusion, NS-MCM-41-Pd has been proven to be a highly efficient catalyst for the cross-coupling reaction of acyl chlorides and triarylbismuths, leading to the formation of a variety of diaryl and alkyl aryl ketones. The use of triarylbismuths as reactants and NS-MCM-41-Pd as the catalyst reveals that the targets of achieving both an atom-efficient and catalyst-recyclable process are reached. Further studies will concentrate on the synthesis of other organic compounds by this economic procedure.

\section{Acknowledgement}

This research was financially supported by the National Science Council of Taiwan (NSC95-2113-M-027-001).

\section{Appendix A. Supplementary data}

Supplementary data associated with this article can be found, in the online version, at doi:10.1016/j.molcata.2009.03.014. 


\section{References}

[1] R.C. Larock, Comprehensive Organic Transformations, Wiley-VCH, New York, 1999.

[2] J. Otera (Ed.), Modern Carbonyl Chemistry, Wiley-VCH, Weinheim, 2000.

[3] For review see: R.K. Dieter, Tetrahedron 55 (1999), 4177-4236.

[4] M. Haddach, J.R. McCarthy, Tetrahedron Lett. 40 (1999) 3109-3112.

[5] N.A. Bumagin, D.N. Korolev, Tetrahedron Lett. 40 (1999) 3057-3060.

[6] G.W. Kabalka, R.R. Malladi, D. Tejedor, S. Kelley, Tetrahedron Lett. 41 (2000) 999-1001.

[7] H. Chen, M.-Z. Deng, Org. Lett. 2 (2000) 1649-1651.

[8] Y. Urawa, K. Ogura, Tetrahedron Lett. 44 (2003) 271-273.

[9] Y. Urawa, K. Nishiura, S. Souda, K. Ogura, Synthesis (2003) 2882-2885.

[10] Y. Nishihara, Y. Inoue, M. Fujisawa, K. Takagi, Synlett (2005) 2309-2312.

[11] B.P. Bandgar, A.V. Patil, Tetrahedron Lett. 46 (2005) 7627-7630.

[12] B. Xin, Y. Zhang, K. Cheng, J. Org. Chem. 71 (2006) 5725-5731.

[13] B. Xin, Y. Zhang, K. Cheng, Synthesis (2007) 1970-1978.

[14] R. Lerebours, A. Camacho-Soto, C. Wolf, J. Org. Chem. 70 (2005) 8601-8604

[15] K. Lee, W.P. Gallagher, E.A. Toskey, W. Chong, R.E. Maleczka Jr., J. Organomet. Chem. 691 (2006) 1462-1465.

[16] D.H.R. Barton, N. Ozbalik, M. Ramesh, Tetrahedron 44 (1988) 5661-5668.

[17] M.L.N. Rao, V. Venkatesh, D.N. Jadhav, Tetrahedron Lett. 47 (2006) 6975-6978.

[18] M.L.N. Rao, V. Venkatesh, D. Banerjee, Tetrahedron 63 (2007) 12917-12926.

[19] A. Corma, Chem. Rev. 97 (1997) 2373-2419.

[20] J.M. Thomas, Angew. Chem. Int. Ed. 38 (1999) 3588-3628.

[21] J.Y. Ying, C.P. Mehnert, M.S. Wong, Angew. Chem. Int. Ed. 38 (1999) 56-77.

[22] R. Anwander, Chem. Mater. 13 (2001) 4419-4438.

[23] A. Biffis, M. Zecca, M. Basato, J. Mol. Catal. A: Chem. 173 (2001) 249-274.

[24] X. He, D. Antonelli, Angew. Chem. Int. Ed. 41 (2002) 214-229.

[25] D.E. De Vos, M. Dams, B.F. Sels, P.A. Jacobs, Chem. Rev. 102 (2002) 3615-3640

[26] D. Trong On, D. Desplantier-Giscard, C. Danumah, S. Kaliaguine, Appl. Catal. A: Gen. 253 (2003) 545-602.

[27] J.M. Thomas, R. Raja, J. Organomet. Chem. 689 (2004) 4110-4124.

[28] C. Li, Catal. Rev. 46 (2004) 419-492.

[29] A. Taguchi, F. Schüth, Micropor. Mesopor. Mater. 77 (2005) 1-45.

[30] F. Hoffmann, M. Cornelius, J. Morell, M. Fröba, Angew. Chem., Int. Ed. 45 (2006) 3216-3251

[31] N.T.S. Phan, M. Van Der Sluys, C.W. Jones, Adv. Synth. Catal. 348 (2006)609-679.

[32] K. Köhler, S.S. Pröckl, W. Kleist, Curr. Org. Chem. 10 (2006) 1585-1601.

[33] C.P. Mehnert, D.W. Weaver, J.Y. Ying, J. Am. Chem. Soc. 120 (1998) 12289-12296.

[34] J.H. Clark, D.J. Macquarrie, E.B. Mubofu, Green Chem. 2 (2000) 53-55.

[35] J. Zhou, R. Zhou, L. Mo, S. Zhao, X. Zheng, J. Mol. Catal. A: Chem. 178 (2002) 289-292.
[36] H. Yang, G. Zhang, X. Hong, Y. Zhu, J. Mol. Catal. A: Chem. 210 (2004) 143-148.

[37] C. Venkatesan, A.P. Singh, J. Catal. 227 (2004) 148-163.

[38] C. González-Arellano, A. Corma, M. Iglesias, F. Sánchez, Adv. Synth. Catal. 346 (2004) 1758-1764

[39] F.-Y. Tsai, C.-L. Wu, C.-Y. Mou, M.-C. Chao, H.-P. Lin, S.-T. Liu, Tetrahedron Lett 45 (2004) 7503-7506.

[40] Y. Ji, S. Jain, R.J. Davis, J. Phys. Chem. B 109 (2005) 17232-17238.

[41] A. Papp, G. Galbács, Á. Molnár, Tetrahedron Lett. 46 (2005) 7725-7728.

[42] F. Alonso, I.P. Beletskaya, M. Yus, Tetrahedron 61 (2005) 11771-11835.

[43] G. Fan, S. Cheng, M. Zhu, X. Gao, Appl. Organomet. Chem. 21 (2007) 670675.

[44] H. Kosslick, I. Mönnich, E. Paetzold, H. Fuhrmann, R. Fricke, D. Müller, G. Oehme, Micropor. Mesopor. Mater. 44-45 (2001) 537-545.

[45] N. Gurbuz, I. Özdemir, B. Çetinkaya, T. Seçkin, Appl. Organomet. Chem. 17 (2003) 776-780.

[46] C. Baleizâo, A. Corma, H. Garcia, A. Leyva, J. Org. Chem. 69 (2004) 439-446.

[47] R. Sayah, K. Glegoła, E. Framery, V. Dufaud, Adv. Synth. Catal. 349 (2007) 373-381.

[48] M. Cai, J. Sha, Q. Xu, J. Mol. Catal. A: Chem. 268 (2007) 82-86.

[49] P. Rollet, W. Kleist, V. Dufaud, L. Djakovitch, J. Mol. Catal. A: Chem. 241 (2005) 39-51.

[50] M. Bandini, R. Luque, V. Budarin, D.J. Macquarrie, Tetrahedron 61 (2005) 9860-9868.

[51] M. Cai, Q. Xu, P. Wang, J. Mol. Catal. A: Chem. 250 (2006) 199-202.

[52] L. Djakovitch, V. Dufaud, R. Zaidi, Adv. Synth. Catal. 348 (2006) 715-724.

[53] F.-Y. Tsai, B.-N. Lin, M.-J. Chen, C.-Y. Mou, S.-T. Liu, Tetrahedron 63 (2007) 4304-4309.

[54] H. Zhao, Y. Wang, J. Sha, S. Sheng, M. Cai, Tetrahedron 64 (2008) 7517-7523.

[55] A.R. Oki, R.J. Morgan, Synth. Commun. 25 (1995) 4093-4097.

[56] G. Will, G. Boschloo, S.N. Rao, D. Fitzmaurice, J. Phys. Chem. B 103 (1999) 8067-8079.

[57] J.R. Doyle, P.E. Slade, H.B. Jonassen, R.N. Rhoda, Inorg. Synth. 6 (1960) 216-219.

[58] M. Wada, S. Natsume, S. Suzuki, A. Uo, M. Nakamura, S. Hayase, T. Erabi, J. Organomet. Chem. 548 (1997) 223-227.

[59] T. Ohe, T. Tanaka, M. Kuroda, C.S. Cho, K. Ohe, S. Uemura, Bull. Chem. Soc. Jpn. 72 (1999) 1851-1855.

[60] H.-P. Lin, C.-P. Tsai, Chem. Lett. 32 (2003) 1092-1093.

[61] R.J. Cox, D.J. Ritson, T.A. Dane, J. Berge, J.P.H. Charmant, A. Kantacha, Chem. Commun. (2005) 1037-1039.

[62] K. Suzuki, H. Kitagawa, T. Mukaiyama, Bull. Chem. Soc. Jpn. 66 (1993) 3729-3734.

[63] R.W. Holder, H.S. Freiman, M.F. Stefanchik, J. Org. Chem. 41 (1976) 3303-3307. 